\title{
Impotentia coeundi as the presenting symptom of a pheochromocytoma
}

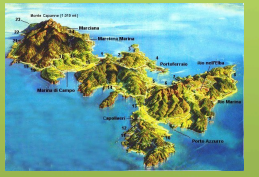

\author{
Plinio Fabiani (1), Stefano Anelli (1), Pablito Bassi (1), Daniela Caniggia (1), \\ Alberto Iurato (2), Fulvio Querci (1), Angelo Testa (3), Giovanna Villani (1)
}

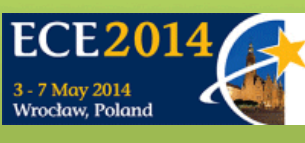

(1) Internal Medicine Department (2) Cardiology Unit (3) Emergency Department - Portoferraio Hospital, Portoferraio, LI, Italy

Introduction. Pheochromocytoma is a rare chromaffin cells derived tumor. It is sometimes referred to as the " $10 \%$ tumor": in about $10 \%$ of cases can be extra-surrenalic, and a similar percentage, malignant, bilateral, familial. It is often suspected as a cause of resistant hypertension, especially if paroxysmal, but rarely suspect is confirmed. Other times, the clinical picture is dominated by severe complications and the diagnosis is delayed because the previous symptomatology was deceitful or misleading, or some of the signs and symptoms were not adequately exploited.

Case report. A 37 year old Caucasian male, with a history of worsening erectile dysfunction, presented to the emergency department for night onset of severe headache and projectile vomiting, complaining of pain in the left hypochondrium, radiating to the ipsilateral lumbar region. The patient was on therapy with tadalafil $5 \mathrm{mg} 1$ tablet once a day and ciprofloxacin $500 \mathrm{mg} 1$ tablet twice a day for one week, on indication of his urologist. The patient reported to suffer from headaches for about one year and worsening impotentia coeundi. Objectively, it was detectable orthopnea, tachypnea, sinus tachycardia with a heart rate of $170 / \mathrm{m}^{\prime}$, blood pressure $250 / 150 \mathrm{mmHg}$, oxygen saturation of haemoglobin: 90\%, diffuse rales on chest auscultation. After treatment with furosemide, diltiazem, urapidil hydrochloride and oxygen, the patient was subjected to computed tomography of skull-brain, chest and abdomen with and without iodinated contrast, echocardiogram, blood tests.

The key findings were: small subcortical left parietal bleeding, multiple pulmonary ground-glass consolidations, and a solid round mass (diameters $113 \times 114 \mathrm{~mm}$ ), well-defined, containing inhomogeneous density areas (necrotic-hemorrhagic pattern), with post-contrast ehancement effect, in close relationship with the tail of the pancreas and the left kidney. The echocardiogram showed left ventricular eccentric hypertrophy (diastolic diameter $57 \mathrm{~mm}$ ) and good contractile function (left ventricular ejection fraction: $64 \%)$. As a collateral finding, the brain vascular system was highlighted even in the absence of iodinated contrast.

Therapeutic strategy: The patient was subsequently stabilized with alpha-blockers, adequately rehydrated and underwent surgery in state of good hemodynamic balance. The dosage catecholamines and metanephrines provided very high values. Histology confirmed the diagnosis of pheochromocytoma.

The current patient condition is that of restitutio ad integrum.

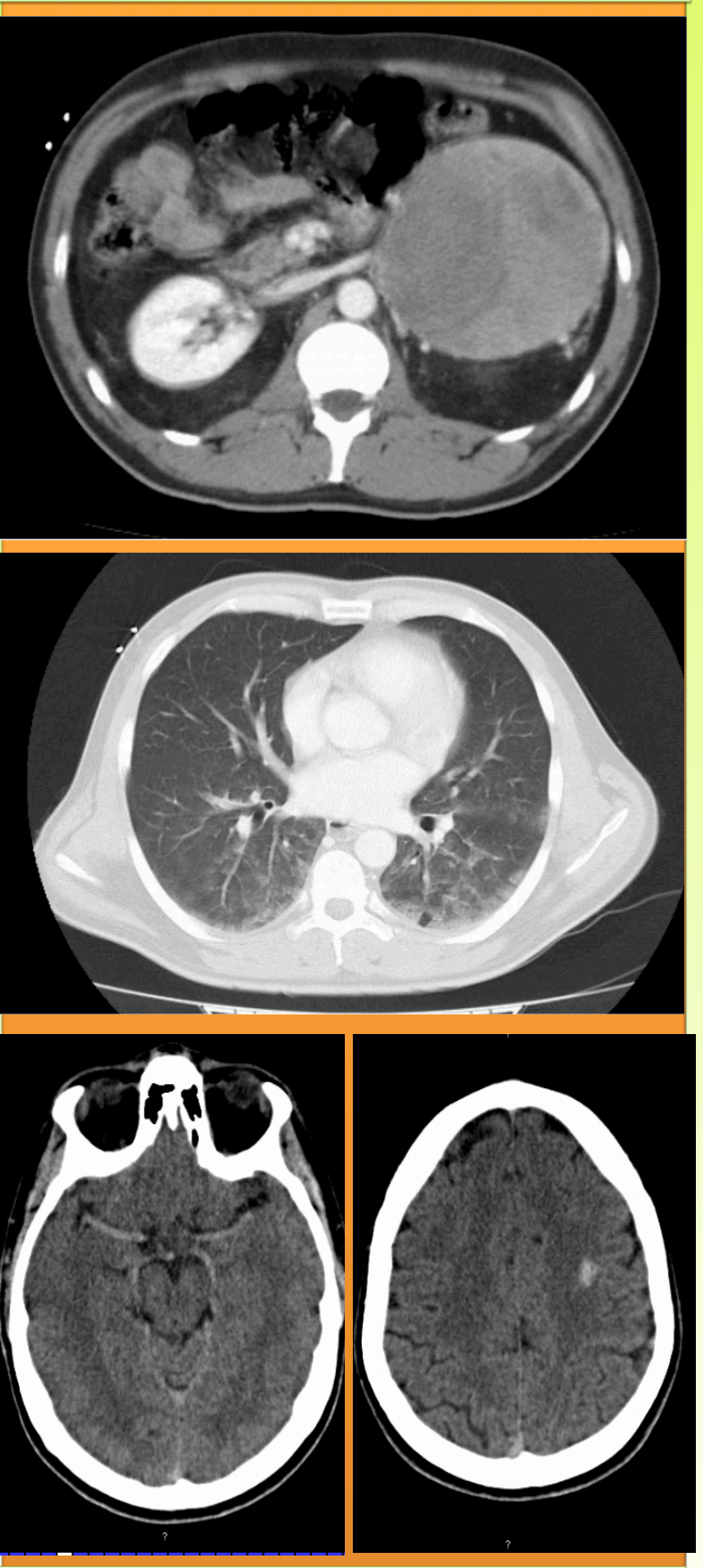

The following are the main features of this clinical case:

1) impotentia coeundi is not normally listed among the classic or more frequent symptoms,

2) the coincident daily intake of tadalafil could have a possible triggering effect on crisis,

3) the high degree hyperadrenergic-induced haemoconcentration provided an unusual contrast-like effect in the vascular brain system. 